\title{
Effects of the Components of Breast Milk on Mucosal Enzyme Activity of the Newborn Small Intestine
}

\author{
A. JONAS, M. OREN, A. DIVER-HABER, B. KAPLAN, AND J. PASSWELL \\ Pediatric Gastroenterolog! Service, the Samuel Jared Kushnik Pediatric Immunology Laboratory, the Chaim \\ Sheba Medical Center and the Sackler School of Medicine, Tel-Aviv University, Istael
}

\begin{abstract}
The effects of the aqueous phase of human breast milk on the disaccharidase activity of newborn rabbit small intestinal mucosal explants were studied in vitro culture. These explants continuously synthesized protein and normal morphology was maintained for the duration of the cultures. Addition of the aqueous phase resulted in significant increase of lactase $(p<0.001)$ and maltase $(p<0.01)$ concentrations in these organ cultures. This effect was dose dependent and was observed whether the organ biopsies were derived from fed or starved newborn rabbits. Further purification of the aqueous phase showed that the active ingredient exerting these effects was lactose. These studies suggest that lactose may have an important function in stabilization of newborn intestinal disaccharidase enzymes. (Pediatr Res 21: 126-130, 1987)
\end{abstract}

\section{Abbreviations}

AP, aqueous phase of breast milk

TCA, trichloracetic acid

BBM, brush border membranes

It is generally assumed that breast milk is specifically tailored to the nutritional and developmental needs of the newborn (1, 2). In vivo studies have shown that colostrum induces enteric mucosal growth, while these effects could not be reproduced by feeding artificial food formulas $(3,4)$. These differences have been attributed to one of the trophic factors known to be present in colostrum and human milk. Epidermal growth factor (5), taurine, gastrin (6), and nongastric intestinal hormones (2), which are all present in human milk, have been considered the most likely candidates for this activity. The relative importance of each of these factors on specific intestinal functions has not been studied extensively.

In vivo studies designed to elucidate the normal process of maturation are limited in their ability to distinguish between endogenous regulatory mechanisms and environmental influences. The stress caused by manipulation when feeding newborns under artificial conditions (4), the consistency and the composition of food (7), and the stress effect of sugar-induced diarrhea (8) have all been shown to promote the premature rise of intestinal mucosal enzymes. Therefore we used an in vitro model of newborn rabbit intestinal organ culture to investigate the influence of breast milk components on mucosal enzyme activity.

Received May 29, 1986: accepted September 15, 1986.

Correspondence A Jonas, Pediatric Gastroenterology, Chaim Sheba Medical Center. Tel Hashomer 52621, Ramat-Gan, Israel.

\section{MATERIALS AND METHODS}

The small intestine of 6-day-old rabbits (Yokneam strain, Yokneam, Israel) with a mean body weight of $160 \mathrm{~g}$ was studied. Each experiment used jejunum of two animals originating from the same litter. Fed (suckled) or 24-h fasted animals were anesthetized, $5 \mathrm{~cm}$ of the proximal jejunum starting $2 \mathrm{~cm}$ distal to the pylorus was isolated under sterile conditions, and mucosal explants were used for organ culture. Adjacent mucosal fragments were obtained for control uncultured mucosal preparation. Organ cultures were performed according to Browning and Trier (9). Mucosal biopsies were oriented villous surface up on stainless steel screens in plastic organ culture dishes (Falcon Plastics, Los Angeles, CA). We usually used three to four biopsies per dish. Tissue culture medium was RPMI 1640 with added $10 \%$ heat inactivated millipore filtered fetal calf serum (Gibco Inc.) with penicillin $100 \mathrm{U} / \mathrm{ml}$ and streptomycin $100 \mu \mathrm{g} / \mathrm{ml}$. The mucosa was incubated in sealed McIntosh jars (Scientific Products Inc., Los Angeles, CA) after they had been gassed with $95 \%$ $\mathrm{O}_{2}-5 \% \mathrm{CO}_{2}$ at $37^{\circ} \mathrm{C}$ for $24 \mathrm{~h}$ unless otherwise stated. Substances to be tested were added at desired concentrations to duplicate dishes. At least two control dishes were included in every experiment.

The viability of mucosal explants was evaluated by histology and amino acid incorporation. Random biopsies were fixed in Bouin's solution, dehydrated, embedded in paraffin, serially sectioned, and stained for light microscopy. Protein synthesis was evaluated according to Kagnoff et al. (10) using ${ }^{14}[\mathrm{C}]$ L-leucine (specific activity $348 \mathrm{mCi} / \mathrm{mmol}$, New England Nuclear Corp., Boston, MA) at $0.5 \mu \mathrm{Ci} / \mathrm{ml}$ as a tracer in the medium. Biopsies cultured for $3,6,12$, and $24 \mathrm{~h}$ were homogenized in $1.5 \mathrm{ml}$ chilled $0.04 \% \mathrm{CaCl}_{2}$. Aliquots of homogenates were saved for protein determination and $1 \mathrm{ml}$ of $30 \%$ TCA and $0.5 \mathrm{ml}$ of $6 \%$ phosphotungstic acid were added.

After $12 \mathrm{~h}$ incubation at $4^{\circ} \mathrm{C}$ the homogenate was centrifuged for $10 \mathrm{~min}$ at $15000 \times \mathrm{g}$. The pellet was washed twice with chloroform-methanol $(1: 1 \mathrm{v} / \mathrm{v})$, dried at room air and dissolved in $0.5 \mathrm{~N} \mathrm{NaOH}$. Protein and the amount of radioactivity was determined by the Lowry procedure and incorporated in the acid precipitable fractions.

Enzyme assays. Mucosal explants from each dish were pooled, rinsed in ice cold $0.9 \% \mathrm{NaCl}$, blotted dry, weighed, and homogenized in water. Maltase and lactase were determined according to Dahlquist (11), alkaline phosphatase by the method of Kelly and Hamilton (12), and protein according to Lowry et al. (13). Mucosal enzymes of organ cultures which had been incubated in medium containing AP were compared to control cultures and the percent increase of each enzyme activity was calculated. Preliminary studies showed that the AP at a final concentration of $10 \%$ resulted in optimal enhancement of mucosal enzyme activity. Therefore, this concentration was used in all subsequent studies. Results of a typical positive assay using the AP of BM is shown in Figure 1. 


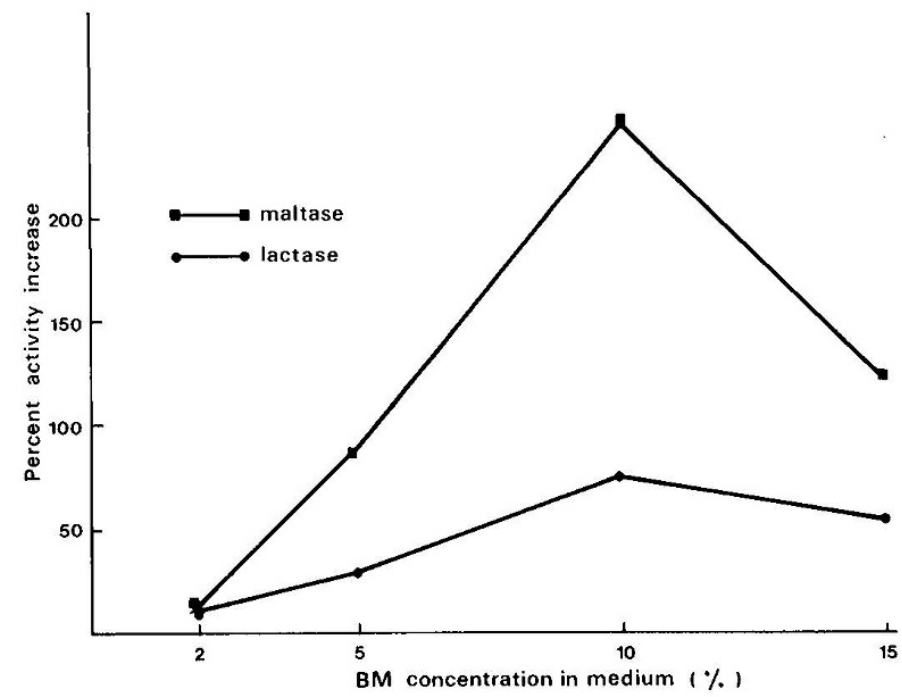

Fig. 1. Specific activity of maltase and lactase in homogenates of mucosal explants from six newborn rabbits cultured for $24 \mathrm{~h}$ in the presence of various concentrations of AP compared to control cultured explants. Mean values of three experiments.

Preparation of $B B M$ and incorporation of glucosamine into brush border glycoproteins. ${ }^{14}[\mathrm{C}]$ glucosamine, $0.5 \mu \mathrm{Ci} / \mathrm{ml}$, (New England Nuclear Corp.) specific activity $325.5 \mu \mathrm{Ci} / \mathrm{ml}$ was added to duplicate dishes of mucosal explants and incubated for 7,12 , and $24 \mathrm{~h}$. Fifty to $80 \mathrm{mg}$ of pooled mucosa was used for BBM preparation according to methods of Schmitz et al. (14). The mucosa was homogenized in $50 \mathrm{mM}$ mannitol and $10 \mathrm{mM} \mathrm{CaCl}$ added. This homogenate was centrifuged at $500 \times g$ and the supernatant was removed and centrifuged again at $23,000 \times g$ for $30 \mathrm{~min}$. The pellet obtained contained the brush border fragments. Homogenates and BBM were assayed for protein and enzyme activity. Incorporated radioactivity was determined in suitable aliquots using $15 \mathrm{ml}$ Bray's solution in a $\beta$-scintillation counter (Packard Instruments Inc., Dowers Grove, IL). Results were expressed as counts per minute/mg tissue protein.

Preparation of human milk. Human milk was collected from nursing mothers 3 to 5 days postpartum by hand expression into sterile $50-\mathrm{ml}$ plastic containers. Fresh milk was immediately centrifuged at $400 \times \mathrm{g}$ at $4^{\circ} \mathrm{C}$ for $40 \mathrm{~min}$. The upper fat layer and the cellular debris were removed. The AP was stored at $-20^{\circ}$ $\mathrm{C}$. Fresh and stored AP were added to the culture medium of intestinal explants at various concentrations. At the termination of the experiments, the mucosal homogenate and brush border enzyme activity was determined and compared to control cultures.

Further purification of the active components in the AP was performed. Samples of AP breast milk were centrifuged at $100,000 \times g$ for $60 \mathrm{~min}$ at $10^{\circ} \mathrm{C}$ (Beckman ultracentrifuge L350 ). The casein pellet was discarded and aliquots of the AP were dialyzed twice against $750 \mathrm{ml} \mathrm{H}_{2} \mathrm{O}$ for 5 and $19 \mathrm{~h}$, respectively at $4^{\circ} \mathrm{C}$. Dialysates were pooled, lyophilized, and redissolved in $2.5 \mathrm{ml}$ of distilled $\mathrm{H}_{2} \mathrm{O}$. Both the protein fraction and dialyzable fraction at concentrations of 5-20\% were tested for effects on intestinal mucosal enzymes. Enhancing activity of mucosal enzymes was retained in the dialysate and purification by chromatography of this fraction of the AP was done. The lyophilisate was applied to a Sephadex G-25 column $(2.6 \times 32 \mathrm{~cm})$. The column was eluted with distilled $\mathrm{H}_{2} \mathrm{O}$ and the effluent was monitored by continuous UV absorbance at $280 \mathrm{~nm}$. Two fractions, the void volume and the retained material of smaller molecular weight, were pooled and lyophilized. The latter was found to retain activity on small intestinal mucosal activity in vitro. This material was further chromatographed on a Sephadex $\mathrm{G}-10$ column $(1.6 \times 80 \mathrm{~cm})$. Elution was performed with distilled
$\mathrm{H}_{2} \mathrm{O}$ and 3.5-ml fractions were collected. The effluent was monitored by UV absorbance at $280 \mathrm{~nm}$ and by the anthrone reaction for carbohydrate (15).

Statistics. Results are expressed as mean \pm SD. Comparison of the experiment to control groups was done using Student's $t$ test.

\section{RESULTS}

The viability of our mucosal explants was confirmed by both histology and the ability of the organ culture to continuously synthesize protein. The histological appearance of intestinal mucosa was well preserved at $24 \mathrm{~h}$. Villi were shorter but the surface epithelium looked normal. The lamina propria was slightly edematous and mild dilation of lymph vessels were seen. In addition, incorporation of radioactive leucine into the acid precipitable fraction of mucosa homogenates was continuously linear for the duration of the 24-h incubation period and unaltered by the addition of $10 \%$ AP (Fig. 2).

The results of 11 experiments comparing uncultured mucosa and cultured mucosa in the presence and absence of $10 \%$ of AP are shown in Figure 3. Six experiments used faster rabbits and five experiments fed animals. The values represent mean \pm SD of 10 to 12 culture dishes each containing three to four mucosal explants. Specific activities of maltase lactase and alkaline phosphatase were lower in homogenates of fasted animals. Mucosal disaccharidases decreased after $24 \mathrm{~h}$ of culture compared to noncultured mucosa in both fed and fasted animals. This effect was significant for lactase levels in fasted animals. Alkaline phosphatase activity increased in all cultured mucosal homogenates.

The addition of $10 \%$ AP resulted in a significant increase of the specific activity of lactase and maltase in both fed and fasted animals compared to the untreated cultured controls. The rise in lactase levels was markedly increased compared to both the control cultured and uncultured mucosa. Alkaline phosphatase values were not significantly influenced by the addition of AP in organ culture although a definite trend toward increased levels was obtained. It should be noted that marked variations in enzyme concentrations both in baseline and in the measured increase to the AP stimulus was observed when the individual experiments were compared. However, the observed stimulation of disaccharidase activity by the AP was consistent within each individual experiment.

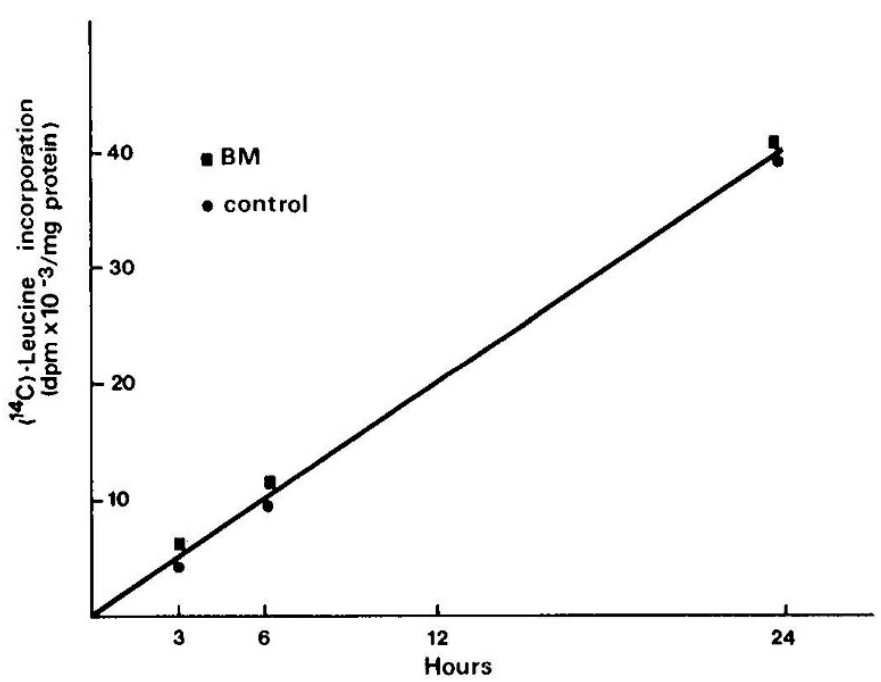

Fig. 2. Incorporation of ${ }^{14} \mathrm{C}$-leucine into acid precipitable fraction of mucosal homogenates obtained from cultured newborn rabbit small intestinal explants in the presence of $10 \%$ AP compared to cultured control mucosa. Mean values of three experiments. 
Isolated BBM from newborn rabbits were of lower purity than those isolated previously in other species using slightly different separation procedures to those reported by ourselves (16) and others (17). This was not due to conditions associated with in vitro culture as shown in Table 1 . The increase in specific activity of brush border enzymes compared to tissue homogenates was the same in cultured and uncultured mucosa.

The incorporation of labeled glucosamine and the specific activity of enzyme in homogenates and the BBM of cultured mucosa with and without the addition of $10 \% \mathrm{AP}$ is shown in Table 2 . We chose the 7-h culture point as a compromise between the still significant but not maximal glucosamine incorporation into $\mathrm{BBM}(18,19)$ and the increase of enzyme activity by AP as determined by our time sequence experiment.

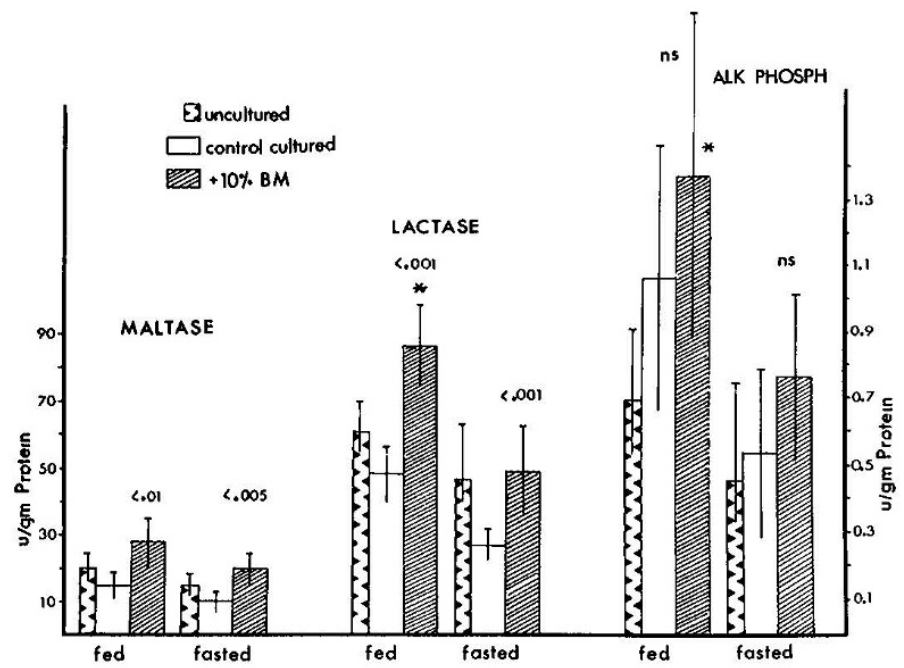

Fig. 3. Specific activities of mucosal enzymes of homogenates obtained from uncultured mucosa and 24-h cultured mucosa in the absence (uhite bars) or presence (striped pane/s) of $10 \%$ AP. Mucosa from fed (suckled) and 24-h fasted newborn rabbits were compared. The results are the mean $\pm \mathrm{SD}$ of 11 experiments. The asterisks compare cultured to uncultured mucosal enzyme values. Figures above columns indicate significance of AP versus control cultured mucosal enzymes.

Table 1. Enzyme purification rates of BBM from $24 \mathrm{~h}$ cultured and uncultured mucose of newborn rabbits (mean $\pm S D$ of 3

\begin{tabular}{ccc}
\multicolumn{3}{c}{ experiments) } \\
\hline $\begin{array}{c}\text { Specific activity BBM/ } \\
\text { specific activity homogenate }\end{array}$ & $\begin{array}{c}\text { Uncultured } \\
\text { mucosa }\end{array}$ & $\begin{array}{c}\text { Cultured } \\
\text { mucosa }\end{array}$ \\
\hline Maltase & $7.8 \pm 1.2$ & $7.0 \pm 2.9$ \\
Lactase & $4.9 \pm 0.9$ & $6.0 \pm 1.9$ \\
Alkaline phosphatase & $8.5 \pm 2.2$ & $7.9 \pm 1.3$ \\
\hline
\end{tabular}

Incorporation of labeled glucosamine did not differ significantly when mucosal explants are cultured in the presence of the AP. An increased synthetic rate is therefore an unlikely explanation. The increase in disaccharidase level in BBM isolated in the presence of the AP was twice the degree of enzyme concentration of mucosal homogenates in the control mucosa. This selective increase of enzyme activity is therefore located to the surface membrane and indicates that by whatever mechanism the AP exerts its effect, it is most active at the surface membrane. Alkaline phosphatase activity of BBM was not significantly affected by the addition of the AP.

In order to assess the sequential pattern of maltase activity during a 24-h organ culture, duplicate culture dishes were removed from the culture jar at various time intervals. Control homogenate showed stable enzyme levels at 3 and $6 \mathrm{~h}$, declining enzyme activity was first observed after $12 \mathrm{~h}$ of culture. Mucosa cultured in the presence of AP showed a continuous rise of enzyme activity for the 24-h culture period, starting at $6 \mathrm{~h}$ culture.

Mucosal enzyme-stimulating activity of the various fractions of breast milk is shown in Table 3. Two samples of breast milk from two different donors were studied. The substance responsible for the increase in the mucosal enzyme activity was present in the AP obtained after centrifugation at $10,000 \times g$, while the upper fat layer and the cellular fraction had no activity. This AP lost its activity after dialysis and the activity was recovered in the dialysate as a small molecular weight fraction $(6-25)$. The dialysate was separated further by chromatography (G-10 Sephadex) and a single fraction with enhancing activity was observed (F2 fraction) (Fig. 4). This material reacted positively by anthrone reaction for carbohydrate and was further identified as lactose by paper electrophoresis, using glucose, fructose, sucrose, and lactose as standards.

Table 3. Increase in specific activity of maltase and lactase of mucosal homogenates cultures in the presence of various fractions of breast milk expressed as percent of control cultured mucosa*

\begin{tabular}{lcc}
\hline & \multicolumn{2}{c}{$\begin{array}{c}\text { Enzyme activity (\% } \\
\text { increase) }\end{array}$} \\
\cline { 2 - 3 } Breast milk & Maltase & Lactase \\
\hline Fat layer & - & - \\
Cell suspension & - & - \\
AP & 93.0 & 55.0 \\
AP postdialysis & - & - \\
Sephadex 625 LMW fraction & 39.0 & 26.0 \\
Sephadex 610 F I & 3.3 & 3.5 \\
F II & 48.7 & 38.5 \\
F III & 2.8 & \\
\hline * Processing of breast milk is described in "Materials and methods."
\end{tabular}

* Processing of breast milk is described in "Materials and methods."

Table 2. Incorporation of ${ }^{14} \mathrm{C}(\mathrm{L})$-glucosamine and specific activity of mucosal and BBM enzymes after 7 in vitro culture without $(C)$ and with added $10 \%$ AP (mean results of 3 experiments in fasted newborn rabbits $\pm S D$ )

\begin{tabular}{|c|c|c|c|c|c|c|c|c|}
\hline \multirow[b]{3}{*}{ Mucosal preparation } & \multicolumn{2}{|c|}{$\begin{array}{c}\text { Incorporated } \\
\text { glucosamine (dpm/mg protein) }\end{array}$} & \multicolumn{6}{|c|}{ Enzyme activity (U/g protein) } \\
\hline & \multirow[b]{2}{*}{$\mathrm{C}$} & \multirow[b]{2}{*}{$\mathrm{BM}$} & \multicolumn{2}{|c|}{ Maltase } & \multicolumn{2}{|c|}{ Lactase } & \multicolumn{2}{|c|}{ Alkaline phosphotase } \\
\hline & & & $\mathrm{C}$ & $\mathrm{BM}$ & $\mathrm{C}$ & $\mathrm{BM}$ & $\mathrm{C}$ & $\mathrm{BM}$ \\
\hline Homogenate & $11.500 \pm 0.800$ & $9.200 \pm 2.200$ & $7.2 \pm 1.7$ & $15.7 \pm 3.2^{*}$ & $26.0 \pm 3.5$ & $48.3 \pm 4.4^{*}$ & $0.89 \pm 0.11$ & $0.96 \pm 0.24$ \\
\hline $\mathrm{BBM}$ & $58.600 \pm 3.700$ & $67.500 \pm 8.900$ & $38.5 \pm 2.3$ & $96.5 \pm 5.3 \uparrow$ & $96.3 \pm 6.0$ & $195.5 \pm 24.3 \ddagger$ & $7.16 \pm 1.45$ & $8.53 \pm 0.65$ \\
\hline
\end{tabular}




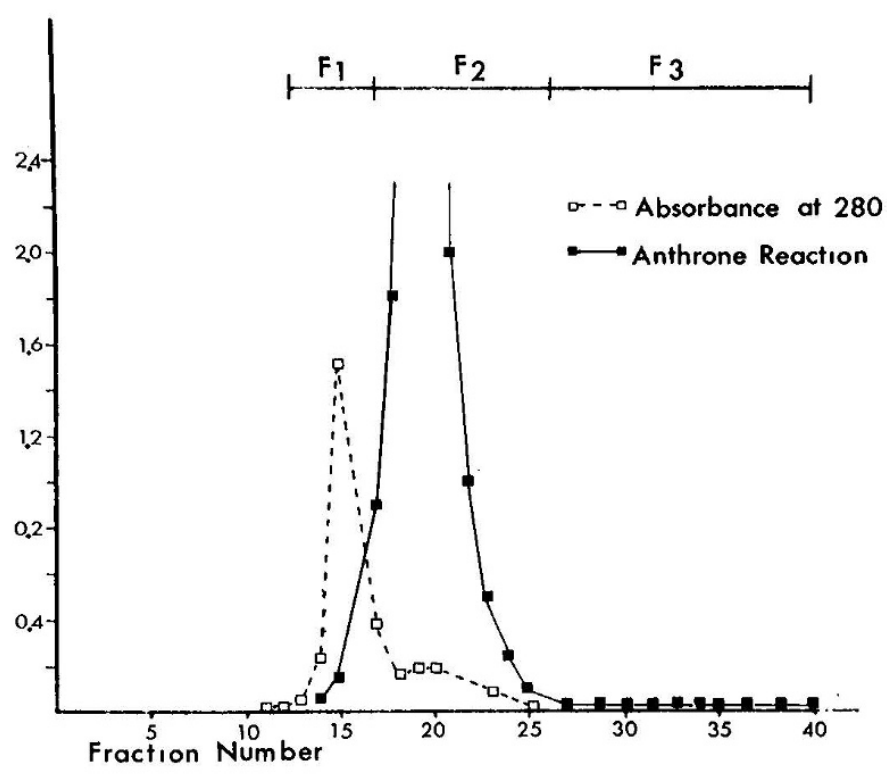

Fig. 4. Gel filtration of breast milk whey dialysate on Sephadex G10. The column $(1.6 \times 80 \mathrm{~cm})$ was eluted with distilled water and fractions of $3.5 \mathrm{ml}$ were collected. Fractions 14 to 17,18 to 27 , and 28 to 40 were pooled.

\section{DISCUSSION}

We have shown that in vitro culture of newborn small intestinal mucosa may be used to determine the effect of individual factors on mucosal activity. The well-preserved morphology and continuous aminoacid incorporation indicated that optimal survival conditions had prevailed for the duration of these experiments (10). It is important to note that differences in the behavior of various enzymes have been observed under these in vitro conditions, e.g. alkaline phosphatase activity increases continuously during a period of 48 -h culture, whereas disaccharidase activity declines during this period. Our results with organ culture of newborn rabbits are in accordance with previous studies, showing stable mucosal disaccharidase levels for the first $12 \mathrm{~h}$ of culture, but decreasing enzyme activity thereafter $(10,18)$. This activity was partly recovered in the culture medium, mainly as particulate bound activity with an identical protein pattern to that of the BBM suggesting that continuous desquamation of the enterocyte membrane had occurred (18).

We found that the addition of $10 \%$ AP to the organ culture medium resulted in a gradual and significant increase in the specific activities of both maltase and lactase compared to control culture mucosa. AP-enhanced enzyme activity was in the range of uncultured mucosal homogenate with the exception of lactase which increased above these values in fed animals. Alkaline phosphatase increased in both control and AP-supplemented medium cultures compared to uncultured mucosa. We suggest that a protective effect of the AP on disaccharidase activity under in vitro conditions is the most reasonable explanation of these results.

The enhanced activity was located to the BBM membrane component compared to total homogenate values, indicating that increased enzymatic activity was predominantly from the surface level of the enterocyte membrane rather than the result of decreased enterocyte losses. Increased synthesis is an unlikely explanation for these findings as the increased specific activity of mucosal enzymes was not associated with an increased incorporation of leucine or glucosamine into mucosal homogenates. Turnover studies of cultured mucosal explants, using double labeled glycoproteins, have indicated a decreased turnover compared to in vivo results, possibly resulting from lack of intralu- minal factors known to influence membrane turnover rates (22). Since we did not measure turnover in our experiments we can only speculate that, due to the lack of evidence of increased synthesis, enhanced enzyme activity can be explained only by decreased loss or membrane stabilization.

The changes in disaccharidase activity observed with the addition of AP are due to lactose as is evident from the isolation of a small molecular fraction comigrating with lactose on paper electrophoresis. Additional experiments using lactose and other carbohydrates on newborn and adult mucosa in organ culture are in progress.

The role of dietary carbohydrates and of lactose in particular in monitoring small intestinal disaccharidase activity is controversial.

Lactose protected lactase activity in vitro and prolonged nursing prevented the naturally occurring decline of lactase activity associated with weaning $(23,24)$. Prolonged lactose feeding of newborn and young rats resulted in increased brush border enzyme activity, which declined after lactose withdrawal (25).

Weaning of rat pups to a lactose-containing diet as the sole source of carbohydrate maintained disaccharidases at higher levels than sucrose feeding (26). The suggested possibility that this is the result of increased gastrin secretion induced by high food intake is not supported.

In preweaning 16-day-old rats artificial formulas containing lactose maintained jejunal lactase activity whereas ileal lactase declined significantly (4). It is possible that this is due, among other reasons, to decreasing lactose concentration along the small intestine.

The postnatal developmental changes in small intestinal enzyme activity are complex and multifactorial, including genetic programing, hormones, and dietary components. Functional changes related to maturation are associated with the emergence of new cell population originating in the proliferative pool of the crypt rather than changes within differentiated cells of the villi (27). Dietary factors modulate enzyme activity in cooperation with hormones (16). Lactose may act in this manner by stabilizing the enterocyte BBM and thus preserving rather than inducing enzyme activity.

Lactose is not a favored candidate to be considered in the dietary management of small intestinal diseases, mostly due to the high frequency of secondary lactase deficiency which occurs frequently in various intestinal diseases. However, in the young animal (28) the adaptive responses to feeding seem to be mostly substrate specific and hormone dependent. Substrate dependency becomes marked under conditions of deprivation or stress, conditions possibly also encountered in our in vitro culture experiments. The favorable responses of the small intestinal disaccharidases observed in our experiments suggested that lactose may have a role in the function of the developing small intestine along with other multiple "growth" factors present in human milk.

\section{REFERENCES}

1. Klagsbrun M, Neumann J. Tapper D 1979 The motogenic activity of human breast milk. J Surg Res 26:417-422

2. Henning SJ 1982 Role of milk born factors in weaning and intestinal development. Biol Neonate 41:265-272

3. Heird WC, Schwarz SM, Hansen IH 1984 Colostrum induced enteric mucosal growth in beagle puppies. Pediatr Res 18:512-515

4. Kow-Yih Yen, Holt PR 1985 Rat milk maintains lactase activity in rat pups where artificial formula do not. Pediatr Res 19:963-967

5. Beaulieu JF, Menard D. Calvert R 1985 Influence of epidermal growth factor on the maturation of the fetal mouse duodenum in organ culture. J Pediatr Gastroenterol Nutr 4:416-481

6. Majumdar APN 1981 Bilateral adrenalectomy: effects of hydrocoritsone and pentagastrin on the activity of intestinal disaccharidases and alkaline phosphatase in weaning rats. Scand J Gastroenterol 16:177-182

7. Pergolizzi E, Lifshitz F, Teichberg S, Wapnir RA 1977 Interaction between dietary carbohydrates and intestinal disaccharidases experimental diarrhea. Am J Clin Nutr 30:482-489 
8. Goda T, Yamada K, Bustamante S, Edmond J, Grimes J, Koldovsky O 1985 Precocious increase of sucrase activity by carbohydrates in the small intestine of suckling rats: significance of the stress effect of sugar-induced diarrhea. $\mathbf{J}$ Pediatr Gastroenterol Nutr 4:468-475

9. Browning TH. Trier JS 1969 Organ culture of mucosal biopsies of human small intestine. J Clin Invest 48:1423-1432

10. Kagnolf MF. Donaldson Jr RM. Trier JS 1972 Organ culture of rabbit smal intestine: prolonged in vitro steady state protein synthesis and secretion and secretory IgA secretion. Gastroenterology 63:541-551

11. Dahlquist A 1964 Method for assay of intestinal disaccharidases. Anal Biochem $7: 18-25$

12. Kelly MH. Hamilton JR 1970 A micro-technique for the assay of intestinal alkaline phosphatase. Results in normal children and in children with celiac disease. Clin Biochem 3:33-43

13. Lowry OM. Rosenbrough NJ, Farr AL, Randall RJ 1951 Protein measurement with the Folin phenol reagent. J Biol Chem 193:265-275

14. Shmit\% J. Preiser H. Maestracci D. Ghosh BK. Cerda JJ. Crane RK 1973 Purification of the human intestinal brush border membrane. Biochem Biophys Acta 323:98-112

15. Roe YH 1975 The determination of sugar in blood or spinal fluid with antrone reagent. J Biol Chem 212:335-343

16. Jonas A. Flanagan DR. Forstner GG 1977 Pathogenesis of mucosal injury in the blind loop syndrome. J Clin Invest 60:1321-1330

17. Simon-Assmann PM. Kedjnger M. Grenier JF, Hadorn B. Haffen K 1982 Control of brush border enzymes by dexamethasone in fetal rat intestine culture in vitro. J Pediatr Gastroenterol Nutr 1:257-265

18. Hauri HP. Kenidger M. Haffen K. Freisburghaus A. Grenier JF. Hadorn B
1977 Biosynthesis of brush border glycoproteins by human small intestinal mucosa in organ culture. Biochem Biophys Acta 467:327-339

19. Cooper JR, Kent PW 1978 The composition and biosynthesis of the glycoproteins and glycolipids of the rabbit small intestinal brush border. Biochem Biophys Acta 513:364-381

20. Simon PM, Kedinger A, Raul F, Grenier JF, Haffen K 1982 Organ culture of suckling rat intestine: comparative study of various hormones on brush border enzymes in vitro. In Vitro 18:339-346

21. Kedinger M, Simon PM, Raul F, Grenier JF, Haffen K 1980 The effect of dexamethasone on the development of rat intestine brush border enzymes in organ culture. Dev Biol 74:9-21

22. Kedinger M, Haffen K, Hauri HP, Grenier JF, Hadord B 1979 Turnover studies of human intestinal brush border membrane glycoproteins in organ culture. Enzyme 24:96-106

23. Lebenthal E, Sunshine P, Kretchmer N 1973 Effect of prolonged nursing on the activity of intestinal lactase in rats. Gastroenterology 64:1136-1141

24. Bolin TD, McKern A. Davis AE 1971 The effect of diet on lactase activity in the rat. Gastroenterology 60:432-437

25. Koldovsky O, Chytil F 1965 Postnatal development of beta-galactosidase activity in the small intestine of the rat. Biochem J 94:266-270

26. Henning SJ, Guerin DM 1981 Role of diet in the determination of jejunal sucrase activity in the weaning rat. Pediatr Res 15:1068-1072

27. Herbst JJ, Koldovsky O 1972 Cell migration and cortisone induction of sucrose activity in jejunum and ileum. Biochem J 126:471-476

28. Lebenthal E, Sunshine P, Kretchmer N 1972 Effect of carbohydrate and corticosteroids on activity of glucosidases in the intestine of the infant rat. Clin Invest 51:1244-1249 